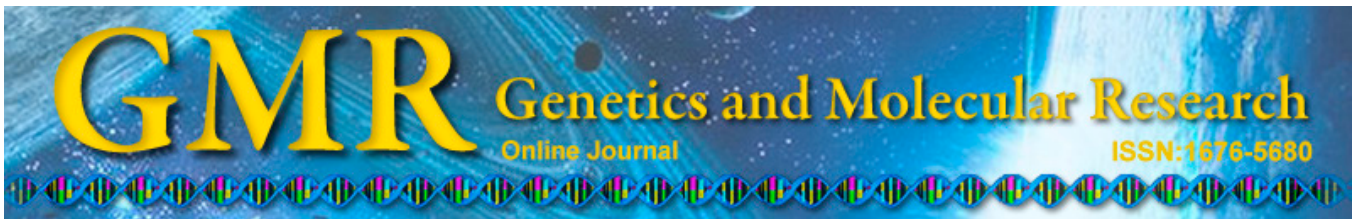

\title{
Association of the FABP2 Ala54Thr polymorphism with type 2 diabetes, obesity, and metabolic syndrome: a population-based case-control study and a systematic meta-analysis
}

\author{
Y. Liu ${ }^{1}$, G. Wu ${ }^{1}$, L. Han ${ }^{1}$, K. Zhao ${ }^{1}$, Y. Qu ${ }^{2}$, A. Xu ${ }^{3}$ and Q. Huang ${ }^{1}$ \\ ${ }^{1}$ College of Life Sciences, Central China Normal University, Wuhan, China \\ ${ }^{2}$ Wuhan Center of Medical Therapeutics, Wuhan, China \\ ${ }^{3}$ Department of Pharmacology and Pharmacy, the University of Hong Kong, \\ Hong Kong, China \\ Corresponding author: Q. Huang \\ E-mail: huangqy@mail.ccnu.edu.cn
}

Genet. Mol. Res. 14 (1): 1155-1168 (2015)

Received August 28, 2014

Accepted January 23, 2015

Published February 6, 2015

DOI http://dx.doi.org/10.4238/2015.February.6.19

\begin{abstract}
Previous studies have reported associations between the functional FABP2 Ala54Thr (rs1799883) polymorphism and type 2 diabetes mellitus (T2DM), obesity, and metabolic syndrome in different populations with conflicting results. We investigated the association between the FABP2 Ala54Thr polymorphism and T2DM (235 cases, 431 controls), obesity (377 cases, 431 controls), and metabolic syndrome (315 cases, 323 controls) by logistic regression analysis in a Chinese study cohort recruited from Yichang, Hubei Province. We then comprehensively reviewed the association of the FABP2 Ala54Thr polymorphism with T2DM, obesity, and metabolic syndrome via meta-analysis. The strength of association was assessed by odds ratios (ORs) with 95\% confidence intervals (CIs). The FABP2 Ala54Thr polymorphism was significantly associated with obesity (AT vs AA:
\end{abstract}


$\mathrm{OR}=2.633,95 \% \mathrm{CI}=1.065-6.663, \mathrm{P}=0.036 ; \mathrm{TT} v s \mathrm{AA}: \mathrm{OR}=4.160$, $95 \% \mathrm{CI}=1.609-10.757, \mathrm{P}=0.003)$ and metabolic syndrome $(\mathrm{TT}$ vs $\mathrm{AA}$ : $\mathrm{OR}=2.273,95 \% \mathrm{CI}=1.242-4.156, \mathrm{P}=0.008)$ by logistic regression with adjustment for covariates. However, no significant association was found between T2DM and the FABP2 Ala54Thr polymorphism. We identified 24 studies on T2DM (4517 cases, 5224 controls), 9 studies on obesity (949 cases, 2002 controls), and 6 studies on metabolic syndrome (2194 cases, 3282 controls) by literature search. The metaanalyses revealed significant associations for metabolic syndrome $(\mathrm{T}$ allele: $\mathrm{OR}=1.179,95 \% \mathrm{CI}=1.015-1.362, \mathrm{P}=0.031)$ and $\mathrm{T} 2 \mathrm{DM}(\mathrm{T}$ allele: $\mathrm{OR}=1.160,95 \% \mathrm{CI}=1.08-1.24, \mathrm{P}<0.001)$, but no association for obesity ( $\mathrm{T}$ allele: $\mathrm{OR}=1.069,95 \% \mathrm{CI}=0.925-1.235, \mathrm{P}=0.367)$.

Key words: $F A B P 2$; Metabolic syndrome; Obesity; Meta-analysis; Type 2 diabetes mellitus

\section{INTRODUCTION}

Metabolic syndrome (MetS) is defined by a clustering of abdominal obesity, an increased serum concentration of triglycerides, a decreased serum concentration of high-density lipoprotein (HDL)-cholesterol, high blood pressure, and an increased fasting blood glucose level. MetS has become a global health concern over the past few decades. Individuals with MetS have a two-fold higher risk of mortality and a three-fold higher risk of experiencing a cardiovascular event, compared with those without MetS (Cheung et al., 2007). The etiology of MetS is highly complex; both genetic and environmental factors are thought to play an important role. Many genetic polymorphisms might be involved in the pathogenesis of MetS. The genes responsible for the metabolism and transport of lipids, the regulation of arterial blood pressure, the transport, regulation, and metabolism of glucose, hormonal regulation, and other factors might contribute to the development of MetS.

Type 2 diabetes mellitus (T2DM), characterized by hyperglycemia, insulin resistance, impaired insulin secretion, and increased hepatic glucose production, is caused by both hereditary factors and environmental factors such as physical inactivity, unhealthy dietary habits, and obesity. According to the latest statistics from the International Diabetes Federation (IDF), the number of diabetes patients will rise from 366 million in 2011 to 552 million by 2030 (Sanghera and Blackett, 2012). The prevalence of obesity has increased at an alarming rate worldwide over past decades. The increasing prevalence of T2DM and obesity constitutes a major public health problem of the 21 st century. As components of MetS, both T2DM and obesity are under strong genetic control.

Fatty acid-binding proteins (FABPs) are members of the super family of small (14-15 $\mathrm{kDa}$ ) intracellular lipid-binding proteins. Intestinal FABP (I-FABP or FABP2) is one of nine different FABPs identified in mammals, besides liver, heart, muscle, adipocyte, epidermal, ileal, brain, myelin, and testis FABPs. The FABP2 gene consists of approximately 3.4 kilobases (kb) located in chromosomal region 4q28-4q31, arranged in four exons containing $~ 700 \mathrm{bp}$ and three introns containing $\sim 2650 \mathrm{bp}$. FABP2 consists of 131 amino acid residues and has a high content of the $\beta$-strand structure. It contains a high affinity-binding site for both saturated and unsaturated long-chain fatty acids, indicating that it might have a role in the absorption and intracellular transport of dietary long-chain fatty acids. 
The most extensively studied polymorphism in the FABP2 gene is the Ala54Thr (rs1799883) in exon 2 that results from a $\mathrm{G}$ to A nucleotide substitution. The Thr54 allelic frequency is $30 \%$ in most populations. The Thr-containing protein has a two-fold higher affinity for long-chain fatty acids than the Ala-containing protein (Wanby et al., 2005). The Ala54Thr polymorphism increases free fatty acid transport and triglyceride secretion in vitro (Yamauchi et al., 2010), which are associated with high levels of fasting insulin. Moreover, previous studies have found that FABP2 is a candidate gene possibly implicated in the pathogenesis of T2DM, MetS, and obesity in different ethnic groups (Table 1).

In this study, we further investigated the association of the FABP2 Ala54Thr polymorphism with T2DM, MetS, and obesity in a Han Chinese cohort recruited from Hubei Province and systematically reviewed the association between FABP2 Ala54Thr and T2DM, MetS, and obesity through a worldwide meta-analysis.

\section{MATERIAL AND METHODS}

\section{Study subjects}

All Hubei Han Chinese subjects were recruited by the government-funded physical examination project from Yichang, Hubei Province (Dehwah et al., 2010). A total of 1173 individuals included 377 obese patients (134 males, 243 females, age $47.85 \pm 9.23$ years) and 431 nonobese people (220 males, 211 females, age $62.15 \pm 10.39$ years); 315 MetS patients ( 88 males, 227 females, age $52.15 \pm 10.35$ years) and 323 controls (171 males, 152 females, age $58.34 \pm$ 10.63 years); and 235 T2DM patients ( 107 males, 128 females, age $54.09 \pm 10.40$ years) and 431 controls (220 males, 211 females, age $62.38 \pm 10.45$ years). The weight, height, and waist and hip circumferences were measured in all individuals. Waist to hip ratio was calculated as waist $(\mathrm{cm}) /$ hip $(\mathrm{cm})$. Measured clinical parameters included fasting blood glucose (FBG), 2-h postprandial blood glucose (PBG), systolic blood pressure (SBP), diastolic blood pressure (DBP), total cholesterol, triacylglycerol, HDL-cholesterol, LDL-cholesterol, and fasting insulin (Table 2).

Body mass index (BMI) was calculated according to the standard ratio of weight $(\mathrm{kg})$ to height squared $\left(\mathrm{m}^{2}\right)$. We set the cutoff point for obesity at a BMI $\geq 25 \mathrm{~kg} / \mathrm{m}^{2}$ and control subjects had a BMI $<25 \mathrm{~kg} / \mathrm{m}^{2}$. According to the criteria of the IDF (Alberti et al., 2005), MetS was confirmed when three or more of the following five criteria were satisfied: i) a BMI $\geq 25$ $\mathrm{kg} / \mathrm{m}^{2}$; ii) a serum triglyceride concentration $\geq 1.65 \mathrm{mM}(150 \mathrm{mg} / \mathrm{dL})$ or drug treatment for elevated triglycerides; iii) a serum HDL-cholesterol concentration $<1.04 \mathrm{mM}(40 \mathrm{mg} / \mathrm{dL})$ for men or $<1.30 \mathrm{mM}(50 \mathrm{mg} / \mathrm{dL})$ for women, or drug treatment for reduced HDL-cholesterol; iv) an $\mathrm{SBP} \geq 130 \mathrm{mmHg}$, a DBP $\geq 85 \mathrm{mmHg}$, or drug treatment for hypertension; and v) a fasting plasma glucose concentration $\geq 5.50 \mathrm{mM}(100 \mathrm{mg} / \mathrm{dL})$ or drug treatment for elevated glucose. Control subjects did not meet any IDF criteria for MetS. T2DM was defined according to the 1997 American Diabetes Association (ADA) criteria: FBG $\geq 7.0 \mathrm{mM}(126 \mathrm{mg} / \mathrm{dL})$ and 2-h $P B G \geq 11.1 \mathrm{mM}(200 \mathrm{mg} / \mathrm{dL})$. The subjects with a family history of maturity-onset diabetes of the young, maternally inherited diabetes, gestational diabetes, mitochondrial diabetes, type 1 diabetes, and other obvious chronic diseases, such as hypertension, coronary heart disease, cancer, and so on were excluded. Healthy controls all had FBG $<6.1 \mathrm{mM}(110 \mathrm{mg} / \mathrm{dL})$ and 2-h PBG $<7.8 \mathrm{mM}$; no family history of T2DM in first-degree relatives; normal blood pressure; normal liver and kidney function; and no chronic heart or lung disease. The survey and sampling received consent, and informed agreements were signed by the subjects themselves. 


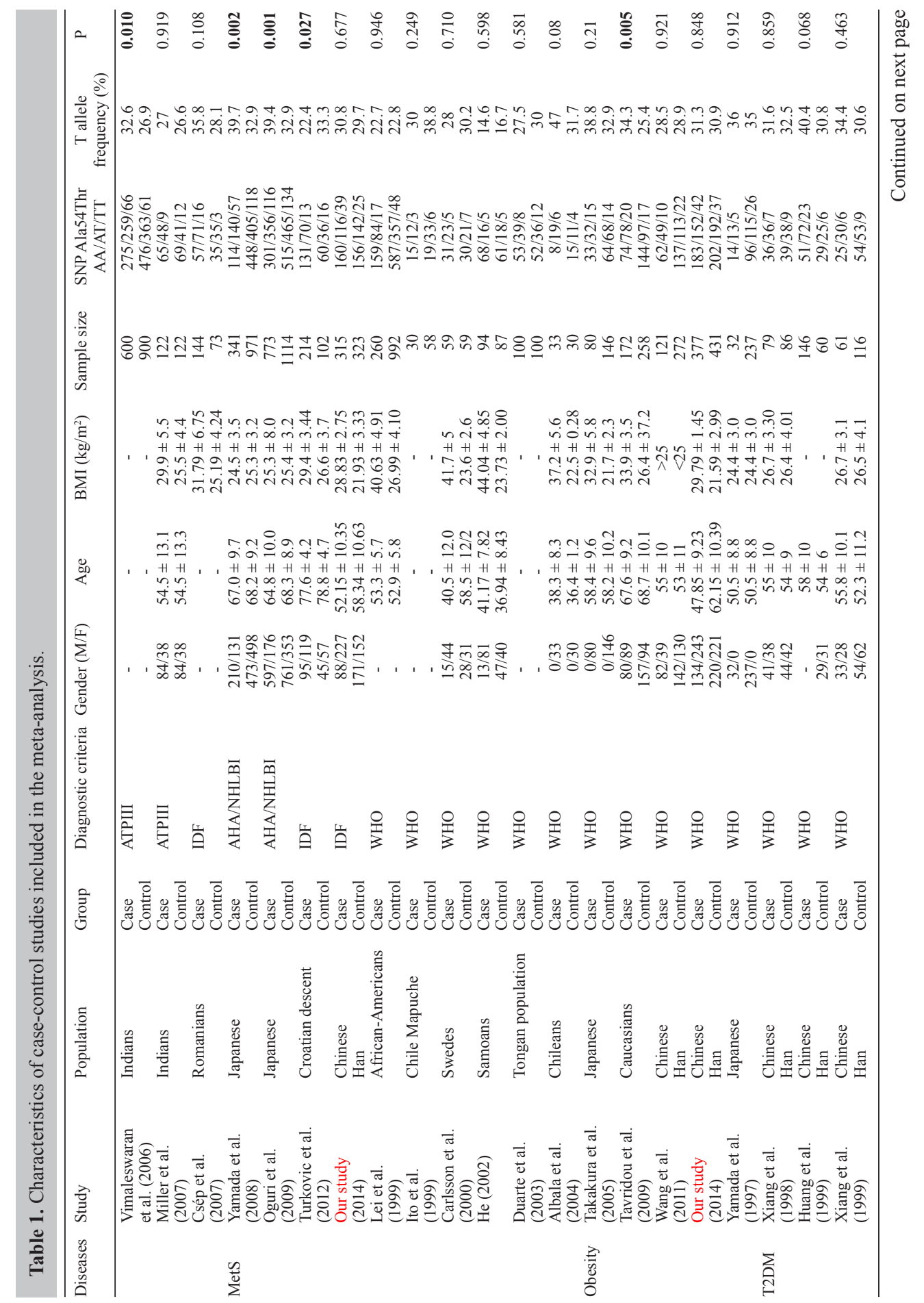




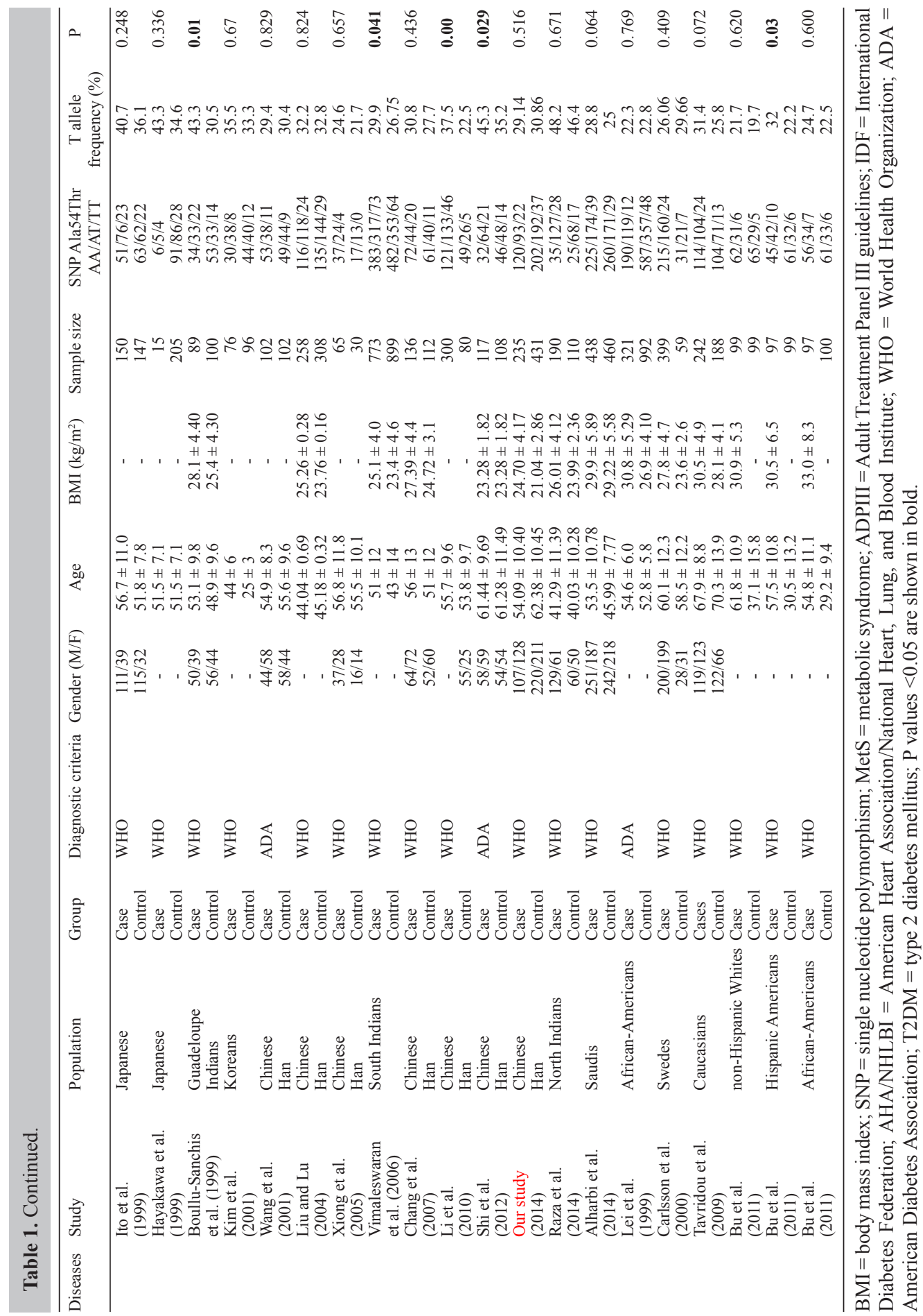




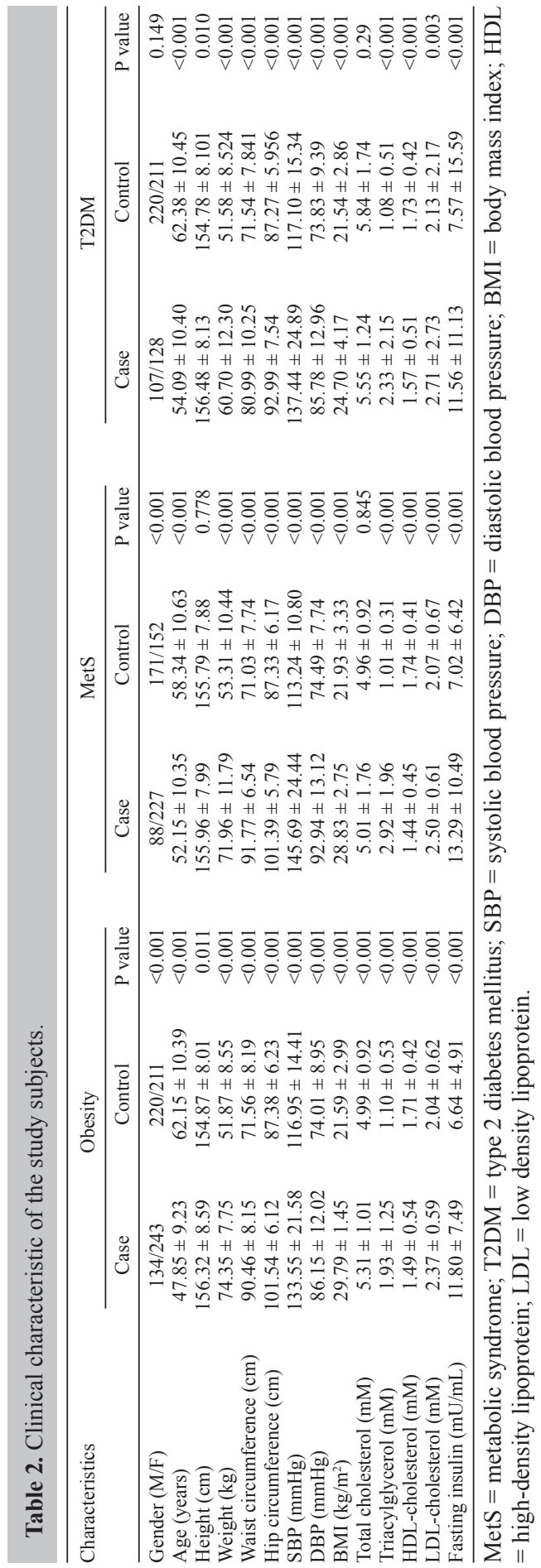




\section{Genotyping}

Genomic DNA was obtained from whole blood leukocytes using the standard phenol/ chloroform method. Detection of the FABP2 Ala54Thr polymorphism was carried out using the polymerase chain reaction (PCR)-restriction fragment length polymorphism technique with forward primers: 5'-CTACCGAGTTTTCTTCCCACC-3'; and reverse primers: 5'-AATT AAACCATCCAATGAAATAGAGC-3'. The PCR reaction mixture consisted of $0.5 \mu \mathrm{L}$ of each primer $(10 \mu \mathrm{M})$ in a total volume of $25 \mu \mathrm{L}$ containing $100 \mathrm{ng}$ DNA template $(50 \mathrm{ng} / \mu \mathrm{L})$, $0.5 \mu \mathrm{L}$ Taq DNA polymerase ( $2 \mathrm{U} / \mu \mathrm{L}), 2.5 \mu \mathrm{L}$ 10X PCR buffer $\left(\mathrm{Mg}^{2+}\right.$ Plus), and $0.5 \mu \mathrm{L}$ dNTP mixture. The PCR conditions were as follows. Initial denaturation at $95^{\circ} \mathrm{C}$ for $5 \mathrm{~min}$ was followed by 40 cycles of PCR under the following conditions: denaturation at $95^{\circ} \mathrm{C}$ for $1 \mathrm{~min}$, annealing at $54^{\circ} \mathrm{C}$ for $1 \mathrm{~min}$, and extension at $72^{\circ} \mathrm{C}$ for $30 \mathrm{~s}$. A final extension step at $72^{\circ} \mathrm{C}$ for $10 \mathrm{~min}$ followed the last PCR cycle. The PCR product $(6 \mu \mathrm{L})$ was digested by $12 \mathrm{U} H h a \mathrm{I}$ restriction enzyme at $37^{\circ} \mathrm{C}$ overnight. The AA genotype is cleaved by HhaI into 207 bp and 169-bp DNA fragments. The TT genotype lacks a $H h a \mathrm{I}$ restriction site and migrates as one 376-bp DNA fragment. All digestion products were resolved on 3\% agarose gel and visualized using ethidium bromide.

\section{Association analysis}

We used $\chi^{2}$ analysis with exact probability to test departure from the Hardy-Weinberg equilibrium (HWE) for the genotype distribution in the cases and controls before association analysis. All continuous variables are reported as means \pm standard deviation. The Student $t$-test was used to compare the difference in continuous variables. The genotype-disease association analyses were performed by logistic regression analysis with or without the adjustment for covariates. A P value less than 0.05 was considered to be statistically significant. Statistical analyses were performed using the SPSS software (version 11.5) for Windows.

\section{Literature and search strategy}

A computerized literature search was conducted to identify the relevant available studies published in English or Chinese from four databases: PubMed, the China National Knowledge Infrastructure, the Database of Chinese Scientific and Technical Periodicals (VIP), and the Wanfang database. All possible studies were identified using the following key words: "FABP2" or "I-FABP"; "obesity"; "gene polymorphism"; "metabolic syndrome" or "MetS"; and "type 2 diabetes", or "type 2 diabetes mellitus," or "T2DM", or "T2D". The references of all publications identified were searched for additional studies. The PubMed option "Related Articles" was used to search for potentially relevant papers. Reference lists in retrieved articles were also screened. Without any language restriction, we only selected published manuscripts (including their online supporting materials). Studies included in the meta-analysis were required to meet all the following criteria: first, the association of the FABP2 Ala54Thr polymorphism with MetS, T2DM, or obesity was assessed; second, each study had case-control groups and had been published as an original study; third, odds ratios (ORs) with $95 \%$ confidence intervals (CIs), or genotype frequency among case and control groups, were provided; fourth, if more than one article was published using the same case series, only the study with the largest sample size or the most recent study was selected. The following information was extracted: 
name of the first author, year of publication, ethnicity of the study population, sample size, numbers of cases and controls, gender and age of enrolled subjects, genotype distribution and minor allele frequency in cases and controls, and $\mathrm{P}$ values for allele frequency (Figure 1). The literature search was updated on June 1, 2013.

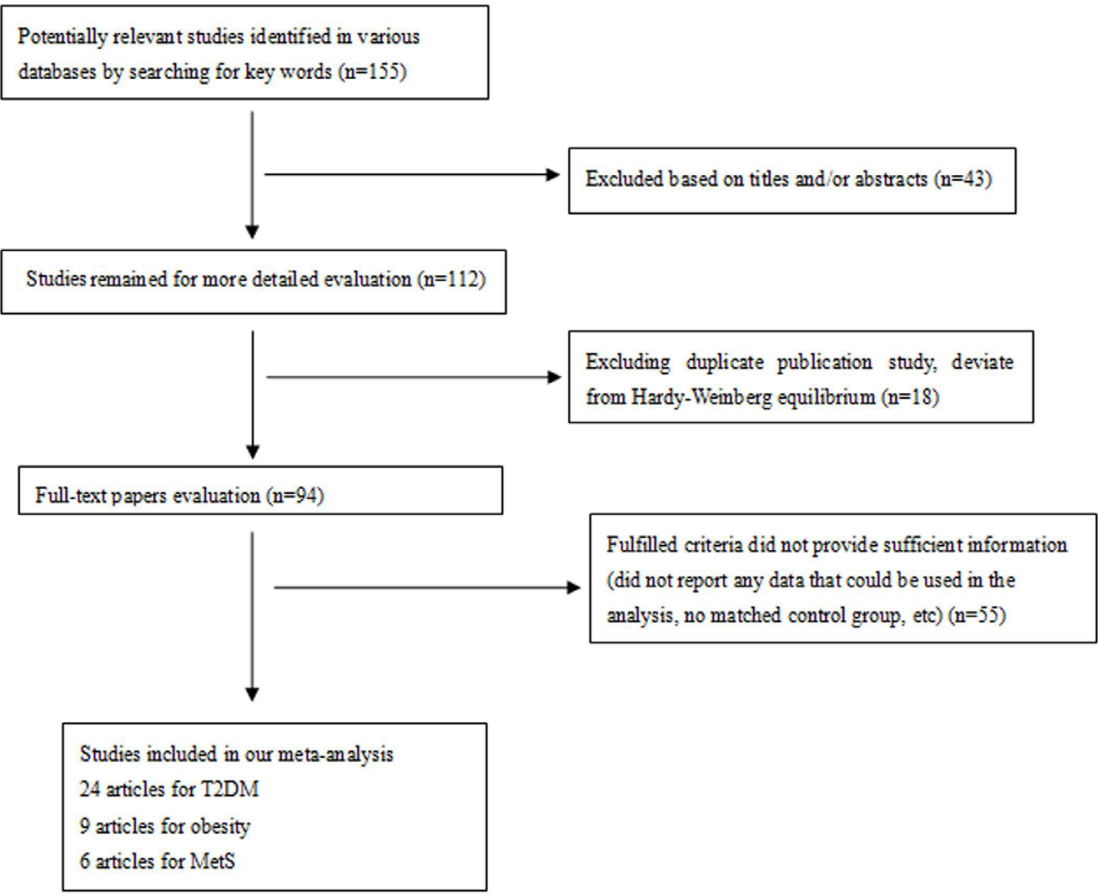

Figure 1. Search strategy for the publications included in our study.

\section{Meta-analysis}

The associations of the FABP2 Ala54Thr polymorphism with MetS, T2DM, and obesity were estimated by calculating pooled ORs and $95 \%$ CIs using the Stata 10.0 software. The ORs were calculated using 2 x 2 contingency tables for each study. Heterogeneity among studies was assessed using the $\chi^{2}$-based Q-test as well as the inconsistency index $\left(\mathrm{I}^{2}\right)$ statistic. Probabilities less than 0.05 were judged significant except for the $\mathrm{I}^{2}$ statistic. Sensitivity analysis was conducted by removing one study at a time and calculating the pooled ORs for the remaining studies. The Z-test was used to calculate the $\mathrm{P}$ value of the overall effect for the meta-analysis. Pooled ORs were computed by the fixed-effects method of MantelHaenszel (Peto method) for data combined under no heterogeneity between studies $(\mathrm{P}>0.1)$. If significant heterogeneity exists between studies $(\mathrm{P} \leq 0.1)$, then the random-effects model of DerSimonian and Laird is appropriate for combined data.

Publication bias was checked by funnel plots and Egger regression analysis. Funnel plots are asymmetric when there is publication bias. The Egger test was performed to measure the funnel plot asymmetry. A significance level of 0.05 was regarded as an indication of potential publication bias. 


\section{RESULTS}

\section{Clinical characteristics of the enrolled subjects}

The clinical characteristics of the subjects enrolled are presented in Table 2. Independent $t$-test analysis showed that the weight, waist circumference, hip circumference, SBP, DBP, BMI, triacylglycerol, and fasting insulin were consistently higher in obesity, T2DM, and MetS patients than in the control group $(\mathrm{P}<0.01)$. The height was significantly higher in T2DM and obesity patients than in the control group, and total cholesterol in obesity patients was higher than in the controls.

\section{Association of the FABP2 Ala54Thr polymorphism with T2DM, obesity, and MetS in Hubei Han Chinese}

Genotypic distributions of the FABP2 Ala54Thr polymorphism were in HWE for obesity, MetS, and T2DM patients and controls. The logistic regression revealed significant associations between the FABP2 Ala54Thr polymorphism and MetS with adjustment for gender and age (TT $v s$ AA: $\mathrm{OR}=2.273,95 \% \mathrm{CI}=1.242-4.159, \mathrm{P}=0.008)$ and without adjustment (TT $v s \mathrm{AA}: \mathrm{OR}=1.910,95 \% \mathrm{CI}=1.092-3.339, \mathrm{P}=0.023)($ Table 3$)$

Table 3. Logistic regression analysis of FABP2 Ala54Thr polymorphism and metabolic syndrome (MetS), obesity, and type 2 diabetes mellitus (T2DM).

\begin{tabular}{|c|c|c|c|c|c|c|c|c|c|}
\hline \multirow[t]{2}{*}{ Diseases } & \multirow[t]{2}{*}{ Genotype } & \multicolumn{2}{|c|}{ Group } & \multicolumn{3}{|c|}{ Unadjusted } & \multicolumn{3}{|c|}{ Adjusted } \\
\hline & & Case & Control & OR & $95 \% \mathrm{CI}$ & $\mathrm{P}$ & OR & $95 \% \mathrm{CI}$ & $\mathrm{P}$ \\
\hline \multirow[t]{3}{*}{ MetS } & AA & 160 & 156 & 1.00 & - & - & 1.00 & - & - \\
\hline & AT & 116 & 142 & 1.521 & $0.879-2.632$ & 0.134 & 1.647 & $0.908-2.988$ & 0.100 \\
\hline & TT & 39 & 25 & 1.910 & $1.092-3.339$ & 0.023 & 2.273 & $1.242-4.159$ & 0.008 \\
\hline \multirow[t]{3}{*}{ Obesity } & AA & 183 & 202 & 1.00 & - & - & 1.00 & - & - \\
\hline & AT & 152 & 192 & 1.253 & $0.771-2.035$ & 0.362 & 2.663 & $1.065-6.663$ & 0.036 \\
\hline & TT & 42 & 37 & 1.434 & $0.878-2.342$ & 0.150 & 4.160 & $1.609-10.757$ & 0.003 \\
\hline \multirow[t]{3}{*}{ T2DM } & AA & 120 & 202 & 1.00 & - & - & 1.00 & - & - \\
\hline & AT & 93 & 192 & 1.001 & $0.564-1.777$ & 0.998 & 0.920 & $0.426-1.984$ & 0.831 \\
\hline & $\mathrm{TT}$ & 22 & 37 & 1.228 & $0.685-2.199$ & 0.491 & 1.211 & $0.553-2.652$ & 0.631 \\
\hline
\end{tabular}

$\mathrm{OR}=$ odds ratio; $\mathrm{CI}=$ confidence interval; $\mathrm{P}$ values $<0.05$ are shown in bold .

Although no significant association was found between obesity and FABP2 Ala54Thr polymorphism by logistic regression without the adjustment for covariates, logistic regression with the adjustment for gender, age, blood pressure, and fasting insulin revealed significant associations (AT $v s \mathrm{AA}$ : $\mathrm{OR}=2.663,95 \% \mathrm{CI}=1.065-6.663, \mathrm{P}=0.036$; $\mathrm{TT} v s \mathrm{AA}$ : $\mathrm{OR}=4.160$, $95 \% \mathrm{CI}=1.609-10.757, \mathrm{P}=0.003)($ Table 3$)$. For T2DM, the FABP2 Ala54Thr polymorphism was not associated with T2DM by logistic regression with or without adjustment for gender, age, blood pressure, weight, and BMI.

\section{Meta-analysis}

For T2DM, 24 studies (Table 1) with complete allele and genotype frequency information were used in our final meta-analysis. Figure 2A shows the forest plot of risk allele OR 
of individual studies and meta-analysis for association between the Ala54Thr polymorphism and T2DM in a total of 4517 T2DM patients and 5224 healthy controls in global populations. Eighteen studies presented a trend of elevated OR for the allele T. Six studies showed a trend in the opposite direction. Because there was no heterogeneity between studies $\left(\mathrm{P}=0.134, \mathrm{I}^{2}\right.$ $=24.7 \%)$, a fixed effect model was performed and generated a pooled $\mathrm{OR}$ of $1.17(95 \% \mathrm{CI}=$ $1.07-1.27, \mathrm{P}<0.001$ ) for the T allele (Figure 2A).

A

Association Study of FABP2 rs 1799883 and T2DM
Comparision: case vs control

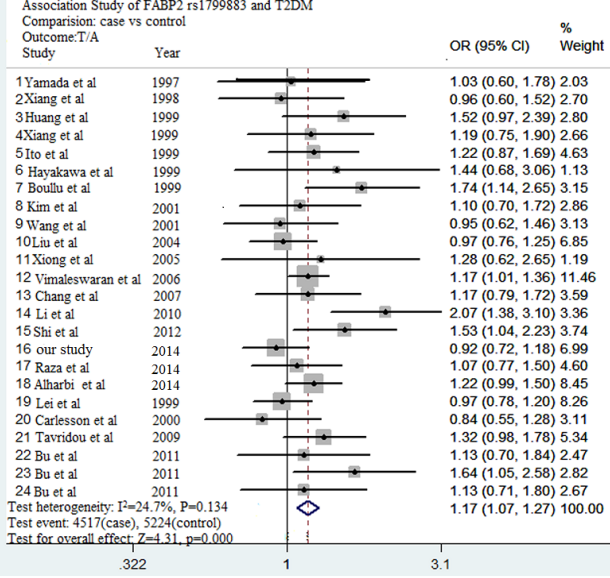

B

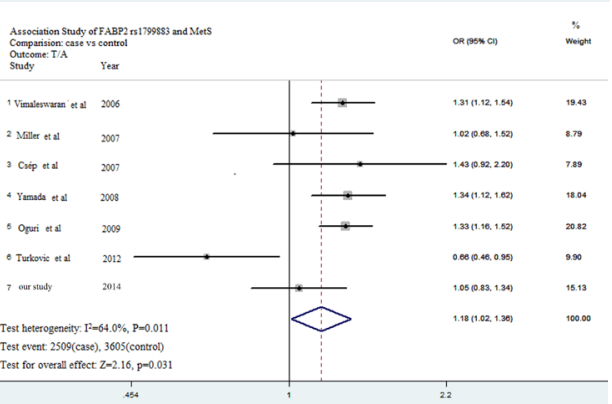

C

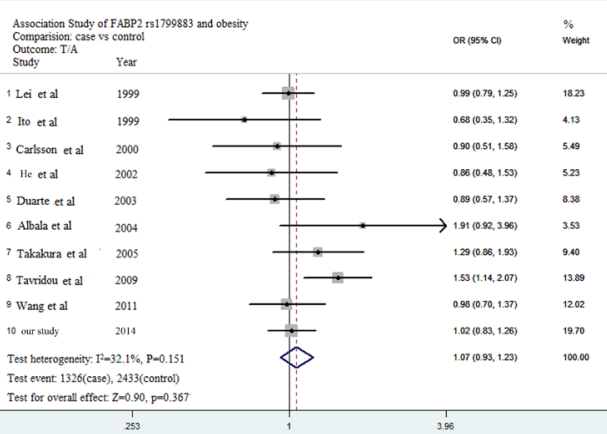

Figure 2. Forest plots of meta-analysis of the association of the FABP2 rs 1799883 polymorphism with type 2 diabetes (A), metabolic syndrome (B), and obesity (C) in the global population. Estimation of odds ratios (ORs) and $95 \%$ confidence intervals (CIs) in each study are displayed as closed squares and horizontal lines, respectively. The size of the black squares reflects the weight of the study in the meta-analysis. The diamonds represent the combined OR, calculated using a random or fixed-effect model, with its $95 \% \mathrm{CI}$. 
Besides our case-control study, we identified 6 association studies with 5476 individuals between the FABP2 Ala54Thr polymorphism and MetS (Table 1). Five studies showed a trend of elevated OR for the allele T (Vimaleswaran et al., 2006; Miller et al., 2007; Csép et al., 2007; Yamada et al., 2008; Oguri et al., 2009). Only one study showed a trend in the opposite direction (Turkovic et al., 2012). A significant association was found for the $\mathrm{T}$ allele $(\mathrm{OR}=$ $1.18,95 \% \mathrm{CI}=1.02-1.36, \mathrm{P}=0.031$, heterogeneity, $\mathrm{P}=0.011, \mathrm{I}^{2}=64.0 \%$ ) (Figure $2 \mathrm{~B}$ ).

We identified 9 studies (2951 individuals) that considered the association between the FABP2 Ala54Thr polymorphism and obesity. As shown in Figure 2C, four studies had a trend of elevated OR for the allele T (Albala et al., 2004; Takakura et al., 2005; Tavridou et al., 2009), and six studies showed a trend in the opposite direction (Lei et al., 1999; Ito et al., 1999; Carlsson et al., 2000; He, 2002; Duarte et al., 2003; Wang et al., 2011). No significant association was found between the FABP2 Ala54Thr polymorphism and obesity (Figure 2C).

\section{Sensitivity analysis}

A sensitivity analysis was conducted by removing one study at a time and calculating the pooled ORs for the remaining studies. This analysis showed that none of the individual studies influenced the pooled ORs, which ranged from $1.29(95 \% \mathrm{CI}=1.08-1.55)$ to 1.41 $(95 \% \mathrm{CI}=1.19-1.69)$ for $\mathrm{T} 2 \mathrm{DM}$ and from $1.009(95 \% \mathrm{CI}=0.897-1.135)$ to $1.089(95 \% \mathrm{CI}$ $=0.945-1.256$ ) for obesity, indicating that the results of the meta-analysis were reliable and stable. However, the results of the meta-analysis for MetS were not stable, being more significant $(\mathrm{P}<0.001, \mathrm{OR}=1.281,95 \% \mathrm{CI}=1.182-1.389)$ after removing Turkovic's study, and nonsignificant after excluding studies by Vimaleswaran et al. (2006), Csép et al. (2007), Yamada et al. (2008), or the one by Mitsutoshi et al. (2007).

\section{Heterogeneity analysis}

A significant heterogeneity was observed for MetS $\left(\mathrm{P}=0.011, \mathrm{I}^{2}=64.0 \%\right)$. Metaregression analysis showed that the age in case groups and control groups contributed to the heterogeneity. The inconsistency index $\mathrm{I}^{2}$ decreased from $64.0 \%$ to $0.0 \%$ after removing Turkovic's study that had the highest age in case groups and control groups, and the lowest $\mathrm{T}$ allele frequency of 0.224 in control groups, indicating that Turkovic's study was responsible for the heterogeneity in the mixed populations.

\section{Publication bias}

Begg's funnel plots were generated to assess publication bias. The Egger test was performed to statistically evaluate funnel plot symmetry. Neither the Begg test nor the Egger test results suggested publication bias for the association of the FABP2 A45T polymorphism and the risk of obesity, MetS, and T2DM (data not shown).

\section{DISCUSSION}

The FABP2 Ala54Thr polymorphism has previously been associated with T2DM, obesity, and MetS with conflicting results (Table 1). Reasons for the lack of consistency across studies included small sample sizes, ethnic differences, and research methodologies. Meta- 
analysis can provide more reliable results than a single study by combining the results from different studies and producing a single estimate of the major effect with enhanced statistical power. In the current study, we examined the association of the functional Ala54Thr polymorphism in the FABP2 gene with T2DM, obesity, and MetS risk in Hubei Han Chinese, and performed a systematical review across different populations by meta-analysis.

For T2DM, no association was found in our Hubei Han Chinese. However, metaanalyses suggested a strong association between the FABP2 Ala54Thr polymorphism and risk of $\mathrm{T} 2 \mathrm{DM}$ in the global populations $(\mathrm{OR}=1.16,95 \% \mathrm{CI}=1.08-1.24, \mathrm{P}<0.001)$. Unlike our meta-analysis on risk of T2DM, Zhao et al. (2010) previously performed a meta-analysis of the FABP2 Ala54Thr polymorphism with insulin resistance and blood glucose in 31 studies with 13,451 subjects. The Thr54 allele is weakly associated with a higher degree of insulin resistance, a higher level of fasting insulin, and a higher level of 2-h blood glucose. Therefore, both meta-analyses with different methods supported the association between the FABP2 Ala54Thr polymorphism and T2DM. Because the Thr54 variant contributes to the excessive absorption of fatty acids, skeletal muscles preferentially use fatty acids for energy rather than glucose, leading to increased glucose levels (Chiu et al., 2001).

Our meta-analyses showed no evidence that the FABP2 Ala54Thr polymorphism is associated with obesity in overall populations. Previously, Zhao et al. (2011) performed metaanalyses of 27 studies with 10,974 subjects on the association between the FABP2 Ala54Thr polymorphism and BMI; their analyses did not support the association. It is worth noting that although no significant association was found between obesity and the FABP2 Ala54Thr polymorphism by logistic regression without the adjustment for covariates, logistic regression with the adjustment for the gender, age, blood pressure, and fasting insulin revealed significant associations (AT vs AA: $\mathrm{OR}=2.633,95 \% \mathrm{CI}=1.065-6.663, \mathrm{P}=0.036$; TT $v s$ AA: $\mathrm{OR}$ $=4.160,95 \% \mathrm{CI}=1.609-10.757, \mathrm{P}=0.003)$ in our Han Chinese study cohort. Therefore, the interactions between the FABP2 Ala54Thr polymorphism and environmental factors/different polymorphic loci might modulate BMI.

For MetS, we conducted the first association study between the FABP2 Ala54Thr polymorphism and MetS in the Chinese Han population, and a significant association was observed for TT $v s$ AA with adjustment for gender and age $(\mathrm{OR}=2.273,95 \% \mathrm{CI}=1.242-4.159, \mathrm{P}=$ 0.008). Six small studies previously conducted in different populations examined the Ala54Thr polymorphism in relation to MetS with inconsistent results. Our meta-analysis supports the association between the FABP2 Ala54Thr polymorphism and MetS. The Thr54 allele may increase the risk of MetS $(\mathrm{OR}=1.176,95 \% \mathrm{CI}=1.015-1.362, \mathrm{P}=0.031)$. To the best of our knowledge, this study represents the first meta-analysis between polymorphisms in the FABP2 gene and MetS. Therefore, both our results and the meta-analyses across different populations throughout the world support the association of the FABP2 Ala54Thr polymorphism with MetS risk.

Our meta-analysis revealed significant between-study heterogeneity only for MetS. The between-study heterogeneity may have arisen for one of the following reasons. First, different diagnostic criteria for MetS: IDF (Csép et al., 2007; Turkovic et al., 2012), American Heart Association/National Heart, Lung, and Blood Institute (AHA/NHLBI) (Yamada et al., 2008; Oguri et al., 2009); and Adult Treatment Panel III guidelines (ATPIII) (Vimaleswaran et al., 2006; Miller et al., 2007). Second, ethnicity differences; the T allele frequencies of controlsubject Croatians, Indians, Romanians, Han Chinese, and Japanese were 0.224, 0.269, 0.281, 0.297 , and 0.329 , respectively. Third, selection bias; the differences in age and gender distributions among the studies included and the difference in sample content might also contribute 
to the heterogeneity. The age of the control subjects ranged from our 52.1 to 78.8 (Turkovic et al., 2012), and sample sizes ranged from 73 (Yamada et al., 2008) to 1114 (Oguri et al., 2009).

Our study has some limitations. First, the sample size was comparatively small and had insufficient statistical power to detect the association. Second, the most common publication bias was caused by a preference for publishing positive, rather than negative, results. Third, since we were not able to obtain the original data, further evaluation of potential interactions, such as the effects of gene-gene and gene-environment interactions were not considered in our current study. Fourth, the present meta-analysis was based primarily on unadjusted effect estimates and the confounding factors (age, gender, etc.) were not controlled for, all of which could have influenced the relationship between the FABP2 Ala54Thr polymorphism and the risk of T2DM, obesity and MetS.

To conclude, the results from our meta-analyses demonstrate the associations between the FABP2 Ala54Thr polymorphism and T2DM and MetS in global populations.

\section{ACKNOWLEDGMENTS}

Research supported by the National Basic Research Program of China ("973" Program, \#2011CB504004), the Self-Determined Research Funds of the Central China Normal University from the colleges' basic research and Operation of Ministry of Education (\#CCNU14Z01003).

\section{REFERENCES}

Albala C, Santos JL, Cifuentes M, Villarroel AC, et al. (2004). Intestinal FABP2 A54T polymorphism: association with insulin resistance and obesity in women. Obes. Res. 12: 340-345.

Alberti KG, Zimmet P, Shaw J and the IDF Epidemiology Task Force Consensus Group (2005). The metabolic syndrome-a new worldwide definition. Lancet 366: 1059-1062.

Alharbi KK, Khan IA, Bazzi MD, Al-Daghri NM, et al. (2014). A54T polymorphism in the fatty acid binding protein 2 studies in a Saudi population with type 2 diabetes mellitus. Lipids Health Dis. 13: 61.

Boullu-Sanchis S, Leprêtre F, Hedelin G, Donnet JP, et al. (1999). Type 2 diabetes mellitus: association study of five candidate genes in an Indian population of Guadeloupe, genetic contribution of FABP2 polymorphism. Diabetes Metab. 25: 150-156.

Bu L, Salto LM, De Leon KJ and De Leon M (2011). Polymorphisms in fatty acid binding protein 5 show association with type 2 diabetes. Diabetes Res. Clin. Pract. 92: 82-91.

Carlsson M, Orho-Melander M, Hedenbro J, Almgren P, et al. (2000). The T 54 allele of the intestinal fatty acid-binding protein 2 is associated with a parental history of stroke. J. Clin. Endocrinol. Metab. 85: 2801-2804.

Chang XT, Hou LJ, Wang ZH, Song GQ, et al. (2007). Association of A54T single nucleotide polymorphism of IFABP gene with serum lipid levels in type 2 diabetes mellitus. Chin. J. Diabetes 15: 285-288.

Cheung BM, Wat NM, Man YB, Tam S, et al. (2007). Development of diabetes in Chinese with the metabolic syndrome, a 6-year prospective study. Diabetes Care 30: 1430-1436.

Chiu KC, Chuang LM and Yoon C (2001). The A54T polymorphism at the intestinal fatty acid binding protein 2 is associated with insulin resistance in glucose tolerant Caucasians. BMC Genet. 2: 7.

Csép K, Vitay M, Dudutz G, Rosivall L, et al. (2007). Correlation of FABP2-A54T polymorphism and the metabolic syndrome in Maros County of Romania. Orv. Hetil. 148: 597-602.

Dehwah MAS, Zhang S, Qu K, Huang H, et al. (2010). KCNQ1 and type 2 diabetes: study in Hubei Han Chinese and meta-analysis in East Asian populations. Genes Genomics 32: 327-334.

Duarte NL, Colagiuri S, Palu T, Wang XL, et al. (2003). Obesity, type II diabetes and the Ala54Thr polymorphism of fatty acid binding protein 2 in the Tongan population. Mol. Genet. Metab. 79: 183-188.

Hayakawa T, Nagai Y, Nohara E, Yamashita H, et al. (1999). Variation of the fatty acid binding protein 2 gene is not associated with obesity and insulin resistance in Japanese subjects. Metabolism 48: 655-657.

He X (2002). A case-control study of 16 polymorphisms in 13 candidate genes and obesity in Samoans. Master's thesis. Division of Epidemiology and Biostatistics, University of Cincinnati, USA. 
Huang M, Yang XJ, Li L, Hu GZ, et al. (1999). Relationship between polymorphism of the human intestinal fatty acid binding protein gene and type 2 diabetic patients with coronary heart disease. Chin. J. Endocrinol. Metab. 15: 290-293.

Ito K, Nakatani K, Fujii M, Katsuki A, et al. (1999). Codon 54 polymorphism of the fatty acid binding protein gene and insulin resistance in the Japanese population. Diabet. Med. 16: 119-124.

Kim SG, Kim CH, Yun SK, Yun YI, et al. (2001). Polymorphism of the uncoupling protein 1 (UCP-1) gene and fatty acid binding protein 2 (FABP2) gene in Korean type 2 diabetic patients. J. Korean Diabetes Assoc. 25: 262-272.

Lei HH, Coresh J, Shuldiner AR, Boerwinkle E, et al. (1999). Variants of the insulin receptor substrate-1 and fatty acid binding protein 2 genes and the risk of type 2 diabetes, obesity, and hyperinsulinemia in African-Americans: the atherosclerosis risk in communities study. Diabetes 48: 1868-1872.

Li Z, Chen LM, Chang BC, Sun P, et al. (2010). Relationship between polymorphism of the human intestinal fatty acid binding protein 2 (FABP2) gene and diabetic nephropathy. Chin. J. Diabetes 18: 182-184.

Liu Y and Lu SH (2004). The study of susceptibility genes of type 2 diabetes mellitus in Northern Chinese. Master's thesis. Inner Mongolia Normal University, Huhehaote.

Miller M, Rhyne J, Chen H, Beach V, et al. (2007). APOC3 promoter polymorphisms C-482T and T-455C are associated with the metabolic syndrome. Arch. Med. Res. 38: 444-451.

Oguri M, Kato K, Yokoi K, Itoh T, et al. (2009). Association of genetic variants with myocardial infarction in Japanese individuals with metabolic syndrome. Atherosclerosis 206: 486-493.

Raza ST, Fatima J, Ahmed F, Abbas S, et al. (2014). Association of angiotensin-converting enzyme (ACE) and fatty acid binding protein 2 (FABP2) genes polymorphism with type 2 diabetes mellitus in Northern India. J. Renin Angiotensin Aldosterone Syst. 15: 572-579.

Sanghera D and Blackett PR (2012). Type 2 diabetes genetics: beyond GWAS. J. Diabetes Metab. 3: 6948.

Shi Q, Yan F, Wang XD and Huang YY (2012). Association between polymorphism of the fatty acid-binding protein 2 gene and type 2 diabetes. Chin. J. Med. Guide 14: 930-933.

Takakura Y, Yoshioka K, Umekawa T, Kogure A, et al. (2005). Thr54 allele of the FABP2 gene affects resting metabolic rate and visceral obesity. Diabetes Res. Clin. Pract. 67: 36-42.

Tavridou A, Arvanitidis KI, Tiptiri-Kourpeti A, Petridis I, et al. (2009). Thr54 allele of fatty-acid binding protein 2 gene is associated with obesity but not type 2 diabetes mellitus in a Caucasian population. Diabetes Res. Clin. Pract. 84: 132-137.

Turkovic LF, Pizent A, Dodig S, Pavlovic M, et al. (2012). FABP 2 gene polymorphism and metabolic syndrome in elderly people of Croatian descent. Biochem. Med. 22: 217-224.

Vimaleswaran KS, Radha V and Mohan V (2006). Thr54 allele carriers of the Ala54Thr variant of FABP2 gene have associations with metabolic syndrome and hypertriglyceridemia in urban South Indians. Metabolism 55: 1222-1226.

Wanby P, Palmquist P, Brudin L and Carlsson M (2005). Genetic variation of the intestinal fatty acid-binding protein 2 gene in carotid atherosclerosis. Vasc. Med. 10: 103-108.

Wang GY, Li QF, Hong TP, Wang YR, et al. (2001). An association study of the human intestinal fatty acid binding protein gene and type 2 diabetic patients. Chin. J. Med. Genet. 19: 447-448.

Wang XS, Bai H, Fan P, Liu R, et al. (2011). Analysis of the FABP2 gene Ala54Thr polymorphism in non-obese and obese Chinese. Sichuan Da Xue Xue Bao Yi Xue Ban 42: 19-23.

Xiang KS, Zheng TS and Jia WP (1998). The relation of intestinal fatty acid binding protein gene Ala54Thr variation to general and regional adipose depots in type 2 diabetes mellitus. Chin. J. Endocrinol. Metab. 6: 356-360.

Xiang KS, Zheng TS, Jia WP, Sun D, et al. (1999). The impact of codon 54 variation in intestinal fatty acid binding protein gene on the pathogenesis of diabetes mellitus in Chinese. Chin. Med. J. 112: 99-102.

Xiong B, Ning YY and Zhu XZ (2005). Relativity between apolipoprotien E, fatty acid binding 2 polymorphism and type 2 diabetes mellitus patients with nephropathy. Clin. Focus 20: 367-370.

Yamada K, Yuan X, Ishiyama S, Koyama K, et al. (1997). Association between Ala54Thr substitution of the fatty acid-binding protein 2 gene with insulin resistance and intra-abdominal fat thickness in Japanese men. Diabetologia 40: 706-710.

Yamada Y, Kato K, Oguri M, Yoshida T, et al. (2008). Association of genetic variants with atherothrombotic cerebral infarction in Japanese individuals with metabolic syndrome. Int. J. Mol. Med. 21: 801-808.

Yamauchi T, Hara K, Maeda S, Yasuda K, et al. (2010). A genome-wide association study in the Japanese population identifies susceptibility loci for type 2 diabetes at UBE2E2 and C2CD4A-C2CD4B. Nat. Genet. 42: 864-868.

Zhao T, Zhao J and Yang W (2010). Association of the fatty acid-binding protein 2 gene Ala54Thr polymorphism with insulin resistance and blood glucose: a meta-analysis in 13451 subjects. Diabetes Metab. Res. Rev. 26: 357-364.

Zhao T, Zhao J, Lv J and Nzekebaloudou M (2011). Meta-analysis on the effect of the Ala54Thr polymorphism of the fatty acid-binding protein 2 gene on body mass index. Nutr. Metab. Cardiovasc. Dis. 21: 823-829. 